Once you have Acrobat Reader open on your computer, click on the Comment tab at the right of the toolbar:

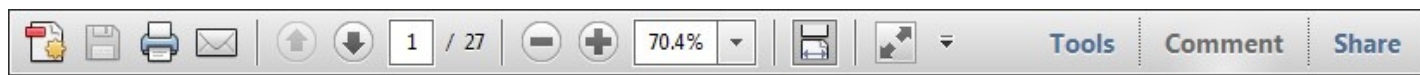

This will open up a panel down the right side of the document. The majority of tools you will use for annotating your proof will be in the Annotations section, pictured opposite. We've picked out some of these tools below:

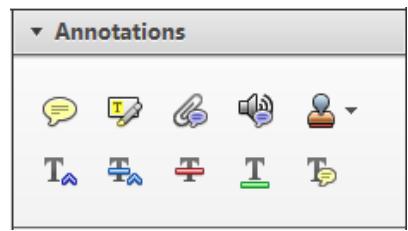

1. Replace (Ins) Tool - for replacing text.

Tistikes a line through text and opens up a text box where replacement text can be entered.

How to use it

- Highlight a word or sentence.

- Click on the Replace (Ins) icon in the Annotations section.

- Type the replacement text into the blue box that appears.

ıdard tramework for the analysis of $\mathrm{m}$ icy-Nevertheless, it also led to exog،

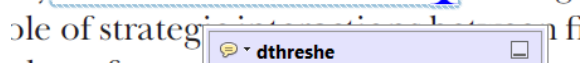
aber of comp 08/06/2011 15:58:17 $\quad$ O is that the $\mathrm{s} 1$, which led of nain compo: be level, are exc nc

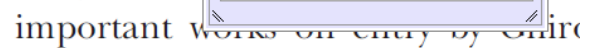
M heneforth) 1 we onen the 'hlarle $\mathrm{t}$

3. Add note to text Tool - for highlighting a section to be changed to bold or italic.

T) Highlights text in yellow and opens up a text box where comments can be entered.

How to use it

- Highlight the relevant section of text.

- Click on the Add note to text icon in the Annotations section.

- Type instruction on what should be changed regarding the text into the yellow box that appears.

namic responses of mark ups ent with the VAR evidence

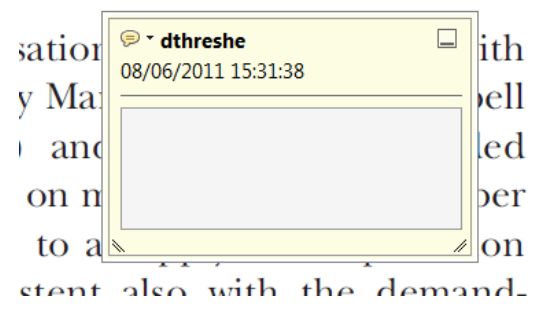

2. Strikethrough (Del) Tool - for deleting text.

T Strikes a red line through text that is to be deleted.

How to use it

- Highlight a word or sentence.

- Click on the Strikethrough (Del) icon in the Annotations section.

there is no room for extra protits al s ups are zero and the number of zet) values are not determined by Blanchard and Kiyotaki (1987), sfect competition in general equilil ts of aggregate demand and supply lassical framework assuming monol een on evorenous number of firme

4. Add sticky note Tool - for making notes at specific points in the text.

Marks a point in the proof where a comment needs to be highlighted.

How to use it

- Click on the Add sticky note icon in the Annotations section.

- Click at the point in the proof where the comment should be inserted.

- Type the comment into the yellow box that appears.

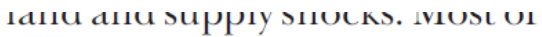

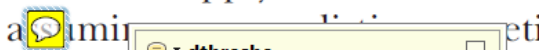

numbe $\mid \begin{aligned} & \ominus \text {-dthreshe } \\ & 08 / 06 / 2011 \text { 15:18:08 }\end{aligned}$

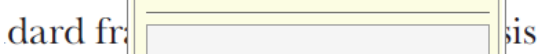

cy. Nev pa

le of st $\square$ wi

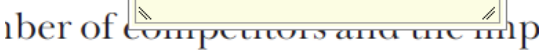

is that the structure of the secto 
5. Attach File Tool - for inserting large amounts of text or replacement figures.

Inserts an icon linking to the attached file in the appropriate place in the text.

\section{How to use it}

- Click on the Attach File icon in the Annotations section.

- Click on the proof to where you'd like the attached file to be linked.

- Select the file to be attached from your computer or network.

- Select the colour and type of icon that will appear in the proof. Click OK.

\section{E N D}

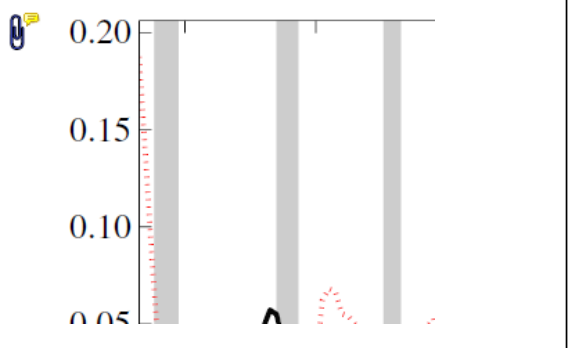

6. Drawing Markups Tools - for drawing shapes, lines and freeform annotations on proofs and commenting on these marks. Allows shapes, lines and freeform annotations to be drawn on proofs and for comment to be made on these marks.

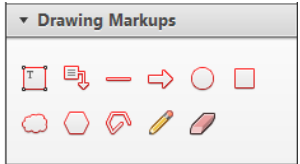

How to use it

- Click on one of the shapes in the Drawing Markups section.

- Click on the proof at the relevant point and draw the selected shape with the cursor.

- To add a comment to the drawn shape, move the cursor over the shape until an arrowhead appears.

- Double click on the shape and type any text in the red box that appears.

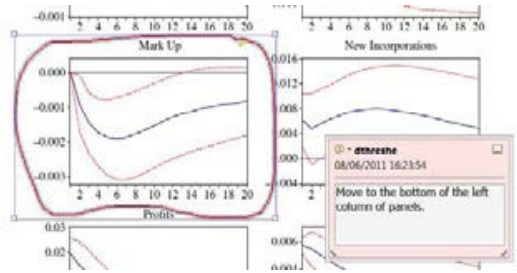




\begin{tabular}{|c|c|c|c|l|l|}
\hline \multirow{2}{*}{$\mathcal{O}$} & J V H & \multicolumn{1}{|c|}{12335} & \multirow{2}{*}{ WILEY } & Dispatch: 15.9.14 & CE: Ashok raj D. \\
\cline { 2 - 3 } \cline { 5 - 5 } & Journal Code & Manuscript No. & & No. of pages: 9 & PE: Indumathi \\
\hline
\end{tabular}

\title{
Clinical course and management of acute and chronic viral hepatitis during pregnancy
}

\author{
A. Licata, D. Ingrassia, A. Serruto, M. Soresi, L. Giannitrapani, G. Montalto, A. Craxì and \\ P. L. Almasio Sezione di Gastroenterologia \& Epatologia, Sezione di Medicina Interna, Di.Bi.M.I.S., Università di Palermo, Palermo, Italy \\ Received June 2014; accepted for publication August 2014
}

SUMMARY. Pregnancy is a para-physiologic condition, which usually evolves without any complications in the majority of women, even if in some circumstances moderate or severe clinical problems can also occur. Among complications occurring during the second and the third trimester very important are those considered as concurrent to pregnancy such as hyperemesis gravidarum, intrahepatic cholestasis of pregnancy, HELLP syndrome and acute fatty liver of pregnancy. The liver diseases concurrent to pregnancy typically occur at specific times during the gestation and they may lead to significant maternal and foetal morbidity and mortality. Commonly, delivery of the foetus, even preterm, usually terminates the progression of these disorders. All chronic liver diseases, such as chronic viral hepatitis, autoimmune hepatitis, Wilson's dis- ease, and cirrhosis of different aetiologies may cause liver damage, independently from pregnancy. In this review we will also comment the clinical implications of pregnancies occurring in women who received a orthotopic liver transplantation (OLT) Therefore, the management of immunosuppressive therapy before and after the delivery in women who received liver transplant is becoming a relevant clinical issue. Finally, we will focus on acute and chronic viral hepatitis occurring during pregnancy, on management of advanced liver disease and we will review the literature on the challenging issue regarding pregnancy and OLT.

Keywords: anti-viral therapy, liver disease, liver transplant, pregnancy.

\section{INTRODUCTION}

Pregnancy is a paraphysiologic condition, which usually evolves without any complications in the majority of women, even if in some circumstances moderate or severe clinical problems can also occur. Concerning the complications occurring during the second and the third trimester of pregnancy, a peculiar attention should be paid to those involving the liver, commonly referred as concurrent to pregnancy. Among these, we can found liver diseases unique to pregnancy, such as hyperemesis gravidarum, intrahepatic cholestasis of pregnancy, HELLP syndrome and

\footnotetext{
Abbreviations: CHB, chronic hepatitis B; CMV, Cytomegalovirus; HAV, hepatitis A virus; HBIG, hepatitis B immunoglobulin; HBV, hepatitis B virus; HCV, hepatitis C virus; HDV, hepatitis D virus; HEV, hepatitis E virus; HSV, Herpes simplex virus; IFN, interferon; MTCT, mother-to-child transmission; NA, Nucleos(t)ides analogues; OLT, orthotopic liver transplantation; PEG-IFN, pegylated interferon.

Correspondence: Piero Luigi Almasio, MD, Gastroenterology \& Hepatology Section, Di.Bi.M.I.S., University of Palermo, Piazza delle Cliniche 2, 90127-Palermo, Italy.

E-mail: piero.almasio@unipa.it
}

acute fatty liver of pregnancy $[1,2]$. However, the majority of liver disease pre-exist to pregnancy (Table 1) [1].

The liver diseases concurrent to pregnancy typically occur at specific times during the gestation and they may lead to significant maternal and foetal morbidity and mortality. Usually, most of the drugs are forbidden in pregnancy, due to their teratogenicity, but the risks and benefits of their use must be considered case by case. Commonly, delivery of the foetus, even preterm, usually terminates the progression of these disorders [2].

All chronic liver diseases, such as chronic viral hepatitis, autoimmune hepatitis, Wilson's disease and cirrhosis of different aetiologies may cause liver damage, independently from pregnancy [3]. On the other hand, the first group is comprehensive of liver diseases that can occur during pregnancy, but not expressly related to it (such as acute viral hepatitis sustained by both major and minor hepatotropic virus) [3]. Furthermore, in this review, we will also comment the clinical implications of pregnancies occurring in women who received a orthotopic liver transplantation (OLT) [4]. In fact, it has recently been reported a significant increase of women that become pregnant after OLT. In United States, more than 3000 females of childbearing age have undergone OLT. Therefore, the management of immunosuppressive therapy before and after the delivery 
Table 1 Liver diseases concurrent or related to pregnancy, according to trimester of gestation and liver involvement

\begin{tabular}{ll}
\hline $\begin{array}{l}\text { Pre-existing or } \\
\text { concurrent liver }\end{array}$ & Viral Hepatitis \\
disease & 1. Acute (HAV, HBV, HCV,HEV, CMV, \\
& HSV) \\
& 2. Chronic (HBV,HCV) \\
& Autoimmune hepatitis \\
& Wilson's disease \\
& Cirrhosis (different aetiology) \\
1st Trimester: \\
Hiseases & Hyperemesis gravidarum \\
& 2nd Trimester: \\
& Intrahepatic cholestasis of pregnancy \\
& 3rd Trimester: \\
& Intrahepatic cholestasis of pregnancy \\
& Eclampsia \\
& HELLP syndrome \\
& Acute fatty liver of pregnancy \\
\hline
\end{tabular}

in women who received liver transplant is becoming a relevant clinical issue [4].

In our review, we will focus on acute and chronic viral hepatitis occurring during pregnancy, on management of advanced liver disease and we will review the literature on the challenging issue regarding pregnancy and OLT.

\section{ACUTE VIRAL HEPATITIS}

Acute viral hepatitis can be acquired during pregnancy (concurrent disease). If we refer only to hepatotropic viruses, the incidence during of pregnancy is almost the same as compared to the general population. Less common during pregnancy is the occurrence of viral hepatitis due to nonhepatotropic viruses.

Acute viral hepatitis is responsible of most of cases of jaundice in pregnant women [1]. In the majority of cases, the clinical course is benign but sometimes cholestasis is manifest and can be prolonged up to puerperium. The major concern is the risk of infection to the foetus (vertical transmission). There is no clear evidence of teratogenic effect of hepatitis viruses in the first trimester [2]. Acute hepatitis acquired during pregnancy does not involve the risk of foetal congenital anomalies, except for Cytomegalovirus (CMV) infection, and the only complication is related to an increase of preterm delivery [2].

\section{Nonhepatotropic viruses}

Cytomegalovirus

Cytomegalovirus infection, which usually evolves asymptomatically, has a high risk of vertical transmission and is responsible for major foetal abnormalities (Table 2) [5]. Commonly, pregnancy is not affected by the clinical course of infection, which is indolent in immunocompetent subjects [5]. Laboratory serological tests are the main clues to diagnose the CMV infection. Prevention is difficult because the virus is ubiquitous and the contact is frequent. Although controversial, some practices might minimize the risk for congenital infection [5]. The saliva and urine of infected children are significant sources of CMV infection. Preventive measures such as frequent hand washing, avoiding to share drinking glasses or eating with utensils of young children, and further stay away from them (avoiding kissing mouth or cheek) appear to be generally acceptable $[5,6]$.

Now, no therapeutic options during pregnancy are available. Recent data obtained from literature have focused the efficacy of preventive administration of CMV immunoglobulins or antiviral drugs (Valacyclovir) to pregnant women with primary CMV infection to reduce the rate of vertical transmission and improve neonatal outcome [7]. The risk of mother-to-foetus transmission is higher when infection is acquired in the first trimester. On the contrary, risk of foetal damages is higher for infections acquired during the last trimester. For this reason, CMV seronegative women must be screened along the pregnancy with serological tests. CMV infection of the mother does not involve any risk. No therapeutic options aimed to protect the foetus are available for women infected during pregnancy, but new strategies are still ongoing. Until now, the only option to evaluate together with the mother in case of foetal infection is the termination of pregnancy, considering the high probability of foetal abnormalities [7].

\section{Herpes simplex virus}

Herpes simplex virus (HSV) infection is rare, but potentially lethal because it may cause fulminant hepatitis, with acute liver failure, especially if it occurs in the third trimester. The rate of mortality in untreated individuals is more than $80 \%$ [8]. Moreover, the hepatitis is anicteric in $90 \%$ of cases, so that the clinical suspicion arises in mostly asymptomatic patients with elevated transaminases (more than 3 times u.l.n.) and normal or mildly elevated bilirubin, often without the typical mucocutaneous lesions $[8,9]$. Serological tests to confirm diagnosis include HSV-IgM and HSVPCR. It has been shown that viral load and transaminases levels are related to disease severity [9]. During pregnancy, the seroconversion rate is about $2 \%$ of women susceptible to HSV $[9,10]$. The serotypes that may cause of hepatitis are HSV-1 and HSV-2 in both primary and latent infections [9].

The premature delivery is not indicated in these cases, as the therapy with acyclovir or vidarabine is effective. The treatment must be started immediately because is life saving for the mother and the foetus [9-11]. Acyclovir is a nucleoside analogue antiviral agent, which is active, and it is recommended for use only when the potential benefit outweighs the potential risks to the foetus [12]. Moreover, in the case of suspected herpes simplex dissemination and 
Table 2 Clinical features of acute hepatitis due to hepatotropic and nonhepatotropic viruses in pregnancy

\begin{tabular}{lllllll}
\hline & CMV & HSV & HAV & HBV & HCV & HEV \\
\hline Latency & Yes & Yes & No & Yes & No & No \\
Symptoms & Asymptomatic or & Potentially & Mild, rarely & Usually & Usually \\
flu-likeYes, if & lethal & lethal & asymptomatic & asymptomatic \\
Foetal Abnormalities & $\begin{array}{c}\text { Contracted as primary } \\
\text { infectionYes }\end{array}$ & Yes, but rare & No & Yes rare,preterm & No & No \\
Vertical transmission & & Yes & Probable & Yes & Yes & Yes \\
\hline
\end{tabular}

hepatic failure, this therapeutic approach is mandatory $[9,11]$.

\section{Hepatotropic viruses}

\section{Hepatitis A virus}

Hepatitis A virus (HAV) can cause clinical complications if it occurs during the second/third trimester of pregnancy. Most of the cases are anicteric and usually mild; fulminant hepatitis is rare [1]. It has been generally accepted that pregnancy itself does not show a negative impact on the course of hepatitis A infection. However, acute HAV hepatitis during pregnancy may be associated with a higher risk of maternal complications and therefore early delivery is indicated only in cases with severe liver dysfunction at the third trimester of gestation [13]. In Western countries, HAV is not frequent. However, in developing countries, there is a high incidence of fulminant hepatitis, probably favoured by a concomitant condition of malnutrition. In serious cases, hospitalization is required especially when nausea and vomiting are severe in the last quarter and induction of premature labour may be occur. However, commonly HAV hepatitis does not represent an indication for Caesarean section, or early termination of pregnancy [14]. Although intrauterine transmission is rare, it has been described in the presence of high levels of viral load at delivery [15]. When HAV infection is diagnosed in the third trimester, the foetus must be protected against the virus by administration of immune globulin within $48 \mathrm{~h}$ before the birth. Breastfeeding is not contraindicated [16].

\section{Hepatitis $E$ virus}

Hepatitis E virus (HEV) hepatitis is rare in Western countries, but it is endemic in several areas of Africa, Asia and Central America, where, if acquired during pregnancy, may show a fulminant course with a mortality rate in one of six pregnancies [17]. Although in Western countries this is not a frequent occurrence, the HEV incidence is increased in Europe as well, especially for genotype 3 [1]. A recent French study has reported that $90 \%$ of acute hepatitis E acquired in the indigenous route, so that it looks like that current HEV epidemiology is going to change [17].

The severe clinical course of HEV infection in pregnancy differs among different Countries. It is conceivable that malnutrition and poor social conditions are the main co-factors promoting this evolution [18,19]. The reason to explain the greater susceptibility to HEV infection in pregnant women is still not known. The hypothesis of the reduced immunological activity and hormonal factors could be considered [20]. Acute HEV infection carries high mortality rates (15-25\%) in pregnant women, especially in the third trimester, in association with acute liver failure, eclampsia and haemorrhages [21]. This is very common in developing countries, due to the emergence of genotype 3 [22]; the level of viremia seems to be likely associated with the severity of the disease during pregnancy [23]. The effect of acute HEV infection on clinical course of pregnancy in Western countries is still not known [22]. Vertical transmission occurs in $50 \%$ of cases and the infection is always symptomatic with high rates of morbidity (hepatitis, prematurity, hypothermia and hypoglycaemia) and mortality in the newborns [21].

No data are available on antiviral drugs for HEV. Treatment is only supportive. There are some reports concerning ribavirin-based treatment, but the teratogenic effect excludes any potential use in pregnant women. In case of life-threatening condition of the mother, termination of pregnancy is the rule [20-22]. Researches to develop an anti-HEV vaccine are underway [2,21].

\section{Hepatitis B virus}

All pregnant women are routinely tested for HBsAg at first visit during gestation to screen hepatitis B virus (HBV) infection. Acute HBV hepatitis is characterized by the absence of clinical complications during the course of pregnancy, but it carries high risk of mother-to-foetus viral transmission. This is particularly frequent if the mother is $\mathrm{HBeAg}$ positive and has been infected during the third trimester of gestation (50-80\%), but the risk of transmission is lower when mother is anti-HBe positive $(25 \%)$, or if she is asymptomatic carrier (5\%) [1]. The risk of transmission is very low in case of maternal infection during the first or second trimester of pregnancy, but increases up to $50-70 \%$ if hepatitis occurs in the third trimester of pregnancy or soon after birth. The main risk factor for transmission is the high viral load [24]. Consequently, antiviral therapy during the third trimester has the goal to reduce 
viremia and so lowering the risk of perinatal transmission [24-26].

Both telbivudine and tenofovir can be taken to prevent intrauterine and perinatal HBV transmission during the last trimester of pregnancy in HBsAg-positive mother with high levels of viremia (serum HBV-DNA $\geq 10^{6}$ copies $/ \mathrm{mL}$ ) but without significant ALT increase. The drug can be discontinued soon after the delivery if breastfeeding is planned or within 3 months.

Infected newborns may become chronic HBsAg carriers in $80-90 \%$ of cases together with subclinical hepatic dysfunction, although they rarely will develop neonatal hepatitis. Perinatal transmission can be prevented with the use of anti-HBV vaccine and in association with hepatitis B immunoglobulin (HBIG) at birth with a percentage of success of about $95 \%$. Patients at high risk of infection can be immunized before or during pregnancy by HBV vaccination without any risk for the foetus [2,24]. As regard HBV/HDV co-infection in pregnancy, there are very few data in literature.

\section{Hepatitis $C$ virus}

The frequency of acute hepatitis $\mathrm{C}$ virus (HCV) infection during pregnancy is approximately calculated $0.4-6.0 \%$ [1]. These percentages increase in groups at high risk of infection (like anti-HIV positive, intravenous drug users). $\mathrm{HCV}$ infection can be acquired during pregnancy, but it does not affect the course of the pregnancy. The risk of vertical transmission is very low (3-10\%) and it is determined by the same risk factors of chronic hepatitis but no therapy is available so far to avoid the contagion [27]. Routine screening is not recommended for HCV infection, but it should be useful at least in 'at risk' groups to start immediately after delivery the therapy [1]. Risk of vertical transmission is higher during delivery, due to contamination with blood fluid, but it can also occur by transplacental crossing. After the delivery, maternal breastfeeding is not absolutely contraindicated because risk of viral transmission is very low during lactation and it is recommended to pay attention to nipple abrasions [1,27] (http://www. 5 cdc.gov/breastfeeding/disease/hepatitis.htm).

\section{CHRONIC VIRAL HEPATITIS}

Chronic viral hepatitis does not adversely affect the course of pregnancy, but it carries the risk of vertical transmission of the virus. Overall, chronic viral hepatitis is the most frequent pre-existing liver disease and they need to be followed through the whole period of pregnancy and overall after delivery.

\section{HBV infection}

$\mathrm{HBV}$ is an important global health problem, because of high risk of perinatal viral transmission. Before the adop- tion of HBIG, approximately 70-90\% of infants born to HBeAg-positive mothers may became chronically infected by HBV [26]. HBV infection does not significantly modify the clinical course of pregnancy either fertility or conception unless the woman has liver cirrhosis or liver failure [28-30]. Moreover, chronic HBV infection does not increase maternal or foetal morbidity and mortality, although a recent study has shown an increased risk of diabetes mellitus, ante-partum haemorrhages and lifethreatening preterm labour [30]. On the other hand, in the presence of cirrhosis, the risk to develop significant perinatal complications and poor pregnancy outcome is higher [31]. Moreover, cirrhotic pregnant women have usually higher spontaneous rates of maternal complications such as placental abruption, gestational hypertension and peripartum haemorrhages [1]. By the contrary, pregnancy does not influence the course of chronic HBV infection and usually it is not considered as a possible worsening factor [24].

Nowadays, the risk of perinatal transmission, which represents in many areas of the world the primary source of persistence of HBV chronic infection, has focused the attention to the management of $\mathrm{HBV}$ infection during pregnancy. The risk is very high in HBeAg-positive patients with high viral load, but conflicting data exist about the potential role of different $\mathrm{HBV}$ genotypes in influencing transmission [24,32].

Among maternal risk factors affecting vertical or perinatal transmission, we also mention placental diseases or complications appearing during labour and breastfeeding, which is another major source of infection [24].

Together with the immunoprophylaxis, the choice of correct antiviral therapy plays a major role in chronic HBV-infected women. Not all available drugs for treatment of chronic HBV infection can be used during pregnancy, and they have an important role to avoid an exacerbation of disease that can occur in case of drug discontinuation, especially soon after the delivery, with high risk of occurrence of fulminant hepatitis causing a life-threatening condition both for mother and foetus [1,25].

Drugs used for the treatment of chronic hepatitis B (CHB) include recombinant interferon (IFN), pegylated interferon (PEG-IFN) and Nucleos(t)ides analogues (NAs). NAs are classified as nucleosides (lamivudine, telbivudine, emtricitabine and entecavir) or nucleotides (adefovir and tenofovir). All these drugs have been approved in Europe for CHB treatment, while PEG-IFN and emtricitabine are not licensed for HBV treatment in most European countries. Because of their possible teratogenicity, only drugs classified in category $\mathrm{C}$ or $\mathrm{B}$ can be used during gestation. According to FDA classification, lamivudine, entecavir and adefovir are classified as ' $\mathrm{C}$ ', while telbivudine and tenofovir are classified as drugs of category B (Table 3). Until now, the more appropriate drug is tenofovir because many data are available about the safety profile in pregnancy. 
Table 3 Drugs for liver diseases and their use in women during pregnancy and after delivery

\begin{tabular}{|c|c|c|c|c|c|}
\hline Class & Drug & $\begin{array}{l}\text { FDA } \\
\text { pregnancy }\end{array}$ & $\begin{array}{l}\text { Effect on } \\
\text { conception }\end{array}$ & Effect on foetus & Breastfeeding \\
\hline \multirow[t]{10}{*}{ Antiviral drugs } & Acyclovir & $\mathrm{B}$ & Unknown & No & Unsafe \\
\hline & Boceprevir & $\mathrm{B}$ & No data & No data & No data \\
\hline & Entecavir & $\mathrm{C}$ & Unknown & No data & Unsafe \\
\hline & Lamivudine & $\mathrm{C}$ & Unknown & $\begin{array}{l}\text { No increases in birth } \\
\text { defects overall }\end{array}$ & Unsafe \\
\hline & Peg-IFN & $\mathrm{C}$ & Teratogenic & Malformation & Unsafe \\
\hline & Ribavirin & $\mathrm{X}$ & Teratogenic & Teratogenic & Unsafe \\
\hline & Telaprevir & $\mathrm{B}$ & No data & No data & Unsafe \\
\hline & Telbivudine & $\mathrm{B}$ & Unknown & $\begin{array}{l}\text { No adverse effects in } \\
\text { animals at doses as } \\
\text { high as } 37 \text { times } \\
\text { human dose }\end{array}$ & $\begin{array}{l}\text { Possibly unsafe, excreted } \\
\text { into the milk of lactating rat }\end{array}$ \\
\hline & Tenofovir & $\mathrm{B}$ & Unknown & No data & Unsafe \\
\hline & Valacyclovir & $\mathrm{B}$ & Unknown & $\begin{array}{l}\text { No teratogenicity but } \\
\text { limited data }\end{array}$ & Unsafe \\
\hline \multirow[t]{2}{*}{ Diuretics } & Spironolactone & $\mathrm{C}$ & No & Unknown & Unsafe \\
\hline & Furosemide & $\mathrm{C}$ & No & No & Unknown \\
\hline \multirow[t]{2}{*}{$\beta$-blockers } & Propranolol & $\mathrm{C}$ & Unknown & $\begin{array}{l}\text { IUGR, bradycardia, } \\
\text { hypoglycaemia, Distress } \\
\text { neonatal distress during } \\
\text { labour }\end{array}$ & Unknown \\
\hline & Nadolol & $\mathrm{C}$ & No & Unknown & $\begin{array}{l}\text { Possible unsafe (mainly } \\
\text { at high dose) }\end{array}$ \\
\hline $\begin{array}{l}\text { Vasoactive } \\
\text { drugs }\end{array}$ & Vasopressin & $\mathrm{C}$ & Unknown & Unknown & Unknown \\
\hline \multirow[t]{5}{*}{$\begin{array}{l}\text { Immunosuppressive } \\
\text { drugs }\end{array}$} & Azathioprine & $\mathrm{D}$ & Unknown & $\begin{array}{l}22 \% \text { malformations, } 45 \% \\
\text { first trimester abortion }\end{array}$ & Unsafe \\
\hline & Cyclosporine & $\mathrm{C}$ & Unknown & Prematurity risk & Unsafe \\
\hline & Tacrolimus & $\mathrm{C}$ & Probable & $\begin{array}{l}\text { Respiratory, renal } \\
\text { dysfunction, birth defects }\end{array}$ & $\begin{array}{l}\text { Possible unsafe, very low } \\
\text { rate excreted in milk }\end{array}$ \\
\hline & Prednisone & $\mathrm{B}$ & No & $\begin{array}{l}\text { Very low rate of } \\
\text { malformation }(4 \%)\end{array}$ & Safe \\
\hline & Mycofenolate & $\mathrm{D}$ & Yes & Birth defects & Unknown \\
\hline
\end{tabular}

Furthermore, several data above safety of tenofovir are reported in HIV patients showing very low rate of congenital abnormalities [33]. By contrast, PEG-IFN is absolutely contraindicated because of high teratogenicity risk. In fact, women or partners of patients treated with PEG-IFN or in childbearing age should use a good contraception system until three to 6 months after stopping antiviral therapy [34].

Regarding to the different pharmacological features and teratogenicity risks of drugs for treating a young woman chronically HBV infected that wish to become pregnant should dispose her pregnancy and should be educated about safety profile of drugs during pregnancy. According to the last EASL guidelines, the therapeutic approach may be different based on the severity of liver damage: in women that want to become pregnant and do not have an advanced fibrosis, it is advisable to delay therapy after the delivery; in women with an advanced fibrosis or cirrhosis, therapy is mandatory [25]. During pregnancy, therapy must be based on a NA of category B, possibly tenofovir. If pregnancy is accidental and not planned, therapy should be adjusted and modified with a NA of category $\mathrm{B}[1]$.

HBV infection can be transmitted from mother-to-foetus at delivery. This risk, as mentioned before, correlates with viral load and HBeAg positivity. The prevention of $\mathrm{HBV}$ perinatal transmission is traditionally based on the combination of passive and active immunization with HBIG and HBV vaccination. Such a strategy, however, may not be effective in a proportion of newborns from highly viremic women (serum HBV-DNA $>10^{6-7}$ copies $/ \mathrm{mL}$ ), which carry a risk of vertical HBV transmission more than $10 \%$ despite administration of HBIG and vaccination. In these cases, the use of NAs before delivery may reduce viral loads and 
therefore improve the effectiveness of HBIG and vaccination [35].

Therapy with lamivudine and, more recently, with telbivudine [36] during the last trimester in HBsAg-positive women with high viral load has been shown to be safe and to reduce the risk of intrauterine and perinatal transmission of $\mathrm{HBV}$ if given in addition to passive and active vaccination by HBIG and $\mathrm{HBV}$ vaccination after delivery. No controlled clinical trial of tenofovir to prevent perinatal transmission has been carried out until now.

There is not contraindication of breastfeeding for HBsAgpositive mother, even if HBV-DNA has been found in maternal milk [37]. No studies are available about safety of NAs use during the breastfeeding. For mothers on antiviral therapy with lamivudine or tenofovir, breastfeeding is not recommended because few data are available about the safety of antiviral exposure during breastfeeding $[33,37]$; however, due to low oral bioavailability of tenofovir in maternal milk, the newborn should not considered to be at risk $[33,38,39]$.

As regarding to $\mathrm{HBV} / \mathrm{HDV}$ co-infection, clinical course of $\mathrm{HDV}$ infection in pregnancy is similar in pregnant and nonpregnant women, although the clinical suspicion of this possible disease should arise in pregnant women with acute or chronic hepatitis $\mathrm{B}$ with a reactivation or hypertransaminasemia, testing for anti-HDV. This is extremely uncommon; however, because the vaccination for hepatitis $\mathrm{B}$, when given to newborns infants, is almost uniformly effective against hepatitis D. Vertical transmission has not been shown, so early delivery is not necessary. Breastfeeding is safe, and vertical transmission can be avoided using HBV immunoprophylaxis [38].

\section{HCV infection}

Prevalence of $\mathrm{HCV}$ infection in pregnant women ranges between $1 \%$ and $2 \%$ in the United States and Europe, but it could increase up to $8 \%$ in some developing countries. HCV mother-to-child transmission (MTCT) has been clearly documented, with reported rates of about $5-10 \%[1,40]$.

Pathogenesis of HCV infection in pregnancy and during the neonatal period remains poorly understood. During gestation, a modulation of immune responses differs between the different stages of pregnancy [41,42]. In fact, at the same time, the maternal immune system must develop tolerance to paternal alloantigens to prevent maternal immune aggression against the foetus and maintain active immunity against HCV to protect both mother and foetus from the infection [41].

Although HCV affects a significant number of women of reproductive age, few studies have examined the impact of chronic HCV infection on pregnancy outcomes. Pregnancy does not seem to adversely affect the clinical course of HCV infection [43]. The majority of pregnant anti-HCV-positive women are asymptomatic. It is possible to observe during pregnancy a decrease of aminotransferases and an increase of HCV viral load, followed by an inversion of parameters during the postpartum period $[1,43]$. It has also been observed an increase of cases with cholestasis of pregnancy in anti-HCV-positive women [44]. The benign course of disease observed during pregnancy is attributed to the production of endogenous IFN by foetus and placenta [45]. The ALT levels decrease in association with viral load increase observed during the third trimester of pregnancy in women chronically infected by HCV could conceivably be explained by a pregnancy-associated decline in immune-mediated hepatocellular destruction and change of immunological state [40,46].

Multiple host factors have been shown to increase the risk of HCV MTCT; some of them are unchangeable, such as elevated viral load, co-infection with HIV, abuse of drugs and alcohol, other are mainly related to delivery management including amniocentesis and prolonged rupture of membranes [42]. Viral transmission can occur both in the uterus and during delivery. Indeed, perinatal HCV transmission is almost restricted to women with detectable HCV-RNA in the peripheral blood and MTCT rarely occurs if the maternal viral load remains below $100000 \mathrm{HCV}$ RNA IU/mL [47]. However, there is a broad overlap in the levels of plasma HCV-RNA between transmitting and nontransmitting mothers [48].

The risk of vertical transmission is related to viral load. Hence, the achievement of viral clearance would be desirable before pregnancy because there are no drugs for $\mathrm{HCV}$ infection usable during gestation to reduce the risk of transmission.

Women with HCV infection can plan a pregnancy, and they must be educated about high teratogenicity risks of therapy during pregnancy. HCV-infected women, treated with standard therapeutic approach, must attend at least 6 months before becoming pregnant. If they accidentally become pregnant, therapy must be stopped and the mother should be informed for the risks of teratogenicity $[1,49,50]$.

HCV-infected pregnant women do not need special monitoring, but only prenatal routine care as noninfected pregnant women. Delivery modalities usually do not influence vertical transmission, and Caesarean section is not considered a modality to prevent vertical transmission [43].

Data on transmission of HCV during lactation are contradictory. It has been suggested a correlation between disease activity (raised transaminases and HCV-RNA positive) and detection of HCV-RNA in breast milk resulting a chance of increased disease transmission by this route $[42,49]$. On the other hand, in several studies, transmission of HCV by breastfeeding has not been demonstrated, so there are no specific contraindications of breastfeeding in HCV-infected women [1,50]. Infected children can be treated with the available options but usually they can be 
treated only after the third year of age because of the adverse effects of treatment on growth [51]. However, spontaneous resolution of infection has been observed both in mother during the postpartum period and in foetus [45].

No data have been published about safety of boceprevir and telaprevir in pregnant women. Their use is actually contraindicated in patients taking oral contraceptive containing ethinylestradiol and norethindrone so that alternative methods of nonhormonal contraception should be used [52].

\section{ADVANCED CHRONIC LIVER DISEASES}

Advanced chronic liver diseases, irrespectively of their aetiology, involve sexual dysfunctions with amenorrhoea and infertility because of hormonal alterations [3,53]. In fact, most women with decompensated cirrhosis are infertile and have menstrual abnormalities, caused by hypothalamic-pituitary dysfunction due to reduced level of gonadotropin-releasing hormone and reduced sex circulating steroid hormones [2]. Moreover, when portosystemic shunts are present, oestradiol and testosterone levels are increased [1].

Once pregnancy has initiated, high risks for mother and baby, such as prematurity, pulmonary hypertension, rupture of varices and bleeding may occur. A study carried out in a large cohort of pregnant women with cirrhosis reported a rate of decompensation of 15\% [54].

However, if liver function is in the normal range and there is no clinically relevant portal hypertension, pregnancy can be carried out. Nevertheless, all these pregnancies should be considered 'at risk', especially for the mothers that can develop variceal bleeding, hepatic failure, jaundice, thrombocytopenia and lineal aneurysm rupture [55]. Foetal loss is also possible. The more dreadful complication is variceal bleeding (20-25\%) [1], especially during the second and third trimester when maternal blood volume is expanded and foetus and uterus dimension are increased, causing compression on inferior cava vein and collateral vessels [56]. For this reason, it is desirable to check each patient at early second trimester with an upper endoscopy and, in case of positive finding, to start prophylactic treatment with beta-blockers [1]. If oesophageal varices are known before pregnancy, they should be treated endoscopically by band ligation. In case of acute bleeding during pregnancy, the approach is also endoscopic [57]. Use of vasopressin is contraindicated in pregnancy [1]. Sclerotherapy seems effective and safe for both, mother and foetus. Variceal band ligation and butyl-cyanoacrylate injection have been executed and resulted safe. Propranolol, which is safe in pregnancy, may be a better option once acute bleeding has been controlled [57]. Caesarean section may reduce the risk of bleeding in patients with large oesophageal varices, but it is not recommended as a routine practice. If possible, a vaginal delivery is desirable [1].

As regard to other sequelae related to cirrhosis (ascites, spontaneous bacterial peritonitis, portosystemic encephalopathy), they rarely occur during pregnancy. Ascites is a very rare event; however, if necessary, depletive therapy is based on sodium restriction and diuretics, as for nonpregnant women with cirrhosis [28]. Hepatic encephalopathy can be caused by particular conditions like hypoxia, infections and gastrointestinal haemorrhages; in these cases, spinal and general anaesthesia during delivery should be avoided for the risk of hypotension and worsening of encephalopathy [28].

\section{PREGNANCY AND LIVER TRANSPLANTATION}

Pregnancy is a real opportunity for women recipients of orthotopic liver transplantation (OLT). Although a successful pregnancy is possible, it must be considered at risk. Maternal and foetal complications can occur, such as preeclampsia, hypertension, anaemia, renal dysfunction, diabetes, infections, prematurity, low weight at birth and miscarriage [2].

Obstetrical syndrome associated with OLT may depend by several factors such as defective deep placentation, uterine vascular bed and side effects of immunosuppressive therapy on uteroplacental arteries, as reported in National Transplantation Pregnancy Registry (NTPR), likewise immunosuppressive therapy can carry risk of miscarriage, prematurity, intrauterine growth retardation and low birth rate [58].

Studies have been performed to compare clinical courses of pregnancies in recipients of liver and renal transplantation, showing that outcomes of pregnancy after OLT are better than those after renal transplantation [59].

Vaginal delivery is possible but, because of high incidence of complications, the practice of Caesarean section is high, about $40 \%$. Similarly, as there is a high incidence of premature delivery, in particular due to significant risk of premature membrane rupture $(40 \%)$, pregnancy course must be closely monitored by a team of transplant hepatologists and experienced obstetrics [2]. Female liver transplant recipients who are planning a pregnancy should be adequately counselled about the optimal timing of become pregnant, mode of delivery and risks associated with immunosuppressive therapy. Furthermore, they should also be recommended on methods of contraception if pregnancy is not planned [59]. As clinical effect of immunosuppressive drugs reaches the peak 1 year after transplant reducing the risk of allograft rejection, it is advised to plan pregnancy about 18 months up to 2 years after transplantation to minimize foetal exposure to high doses of immunosuppressant drugs [2,59]. The use of immunosuppressive therapy after liver transplantation is unavoidable. All immunosuppressive agents cross the placenta and enter into foetal circulation with potentially dangerous effects in utero. The immunosuppressive agents $\mathbf{6}$ 
such as azathioprine, cyclosporine and mycophenolic acid have been shown to be teratogenic in animals. The risk of birth defects is almost similar for all agents; some drugs, like calcineurin inhibitors can lead to prematurity risk and others (like cyclosporine) could have their effect on renal function increasing the risk of pre-eclampsia [58]. Tacrolimus seems to give lower incidence of complications gaining a better control of hepatic function [60]. Obviously, hepatic function must be strictly checked along the whole pregnancy and every abnormalities should be managed in the same way as in nonpregnant women [2].
As regard to breastfeeding mothers with OLT can safely use prednisone or other glucocorticoids. The infant exposure of tacrolimus with milk is very low, and therefore, its administration may be compatible with breastfeeding. Data collected from the NTPR indicate no adverse outcomes in infants who were breastfed during maternal cyclosporine use; insufficient evidence is present in the literature about azathioprine's teratogenicity [2]. Nevertheless, it is advised to avoid breast feed in the first few months post-transplantation where immunosuppressive therapy is at high serum level.

\section{REFERENCES}

1 Hay JE. Liver disease in pregnancy. Hepatology 2008; 47: 1067-1076.

2 Hammoud GM, Almashhrawi AA, Ahmed KT, Rahman R, Bah JA. Liver diseases in pregnancy: liver transplantation in pregnancy. World J Gastroenterol 2013; 19: 76477651.

3 Lee M, Brady W. Liver disease in pregnancy. World $J$ Gastroenterol 2009; 15: 897-906.

4 Alvaro E, Jimenez LC, Palomo I et al. Pregnancy and orthotopic liver transplantation. Transplant Proc 2013; 45: 1966-1968.

5 Lazzarotto T, Guerra B, Gabrielli L, Lanari M, Landini MP. Update on the prevention, diagnosis and management of cytomegalovirus infection during pregnancy. Clin Microbiol Infect 2011; 17: 12851293.

6 Nigro G, Adler SP, La Torre R, Best AM; Congenital Cytomegalovirus Collaborating Group. Passive immunization during pregnancy for congenital cytomegalovirus infection. $N$ Engl J Med 2005; 353: 1350-1362.

7 Jacquemard F, Yamamoto M, Costa JM et al. Maternal administration of valaciclovir in symptomatic intrauterine cytomegalovirus infection. BJOG 2007; 114: 1113-1121.

8 Norvell JP, Blei AT, Jovanovic BD, Levitsky J. Herpes simplex virus hepatitis: analysis of the published literature and institutional cases. Liver Transpl 2007; 13: 1428-1434.

9 Brown ZA, Selke S, Zeh J et al. The acquisition of herpes simplex virus during pregnancy. $N$ Engl J Med 1997; 337: 509-515.

10 Beersma MF, Verjans GM, Metselaar $\mathrm{HJ}$, Osterhaus $\mathrm{AD}$, Berrington WR, van Doornum GJ. Quantification of viral DNA and liver enzymes in plasma improves early diagnosis and management of herpes simplex virus hepatitis. J Viral Hepat 2011; 18: e160-e166.

11 Allen RH, Tuomala RE. Herpes simplex virus hepatitis causing acute liver dysfunction and thrombocytopenia in pregnancy. Obstet Gynecol 2005; 106: 1187-1189.

12 Glaxo Wellcome Inc. Zovirax (acyclovir) Product Information. Boronia, Vic.: Glaxo Wellcome Inc, 1996.

13 Martin A, Lemon SM. Hepatitis A virus: from discovery to vaccines. Hepatology 2006; 43(2 Suppl. 1): S164-S172.

14 Motte A, Blanc J, Minodier P, Colson P. Acute hepatitis A in a pregnant woman at delivery. Int J Infect Dis 2009; 13: e49-e51.

15 Leikin E, Lysikiewicz A, Garry D, Tejani N. Intrauterine transmission of hepatitis A virus. Obstet Gynecol 1996; 88: 690-691.

16 Fiore AE, Shapiro CN, Sabin K et al. Hepatitis A vaccination of infants: effect of maternal antibody status on antibody persistence and response to a booster dose. Pediatr Infect Dis J 2003; 22: 354-359.

17 Renou C, Moreau X, Pariente A et al. A national survey of acute hepatitis $\mathrm{E}$ in France. Aliment Pharmacol Ther 2008; 27: 10861093.

18 Navaneethan U, Mohajer MA, Shata MT. Hepatitis E and pregnancy: understand the pathogenesis. Liver Int 2008; 28: 1190-1198.

19 Tsega E, Krawczynski K, Hansson BG, Nordenfelt E. Hepatitis E virus infection in pregnancy in Ethiopia. Ethiop Med J 1993; 31: 173-181.

20 Pal R, Aggarwal R, Naik SR, Das V, Das S, Naik S. Immunological alterations in pregnant women with acute hepatitis E. J Gastroenterol Hepatol 2005; 20: 1094-1101.

21 Aggarwal R, Jameel S, Hepatitis E. ???????????. Hepatology 2011; 54: 2218-2226.

22 Sclair SN, Schiff ER. An update on the hepatitis E virus. Curr Gastroenterol Rep 2013; 15: 304.

23 Borkakoti J, Hazam RK, Mohammad A, Kumar A, Kar P. Does high viral load of hepatitis $\mathrm{E}$ virus influence the severity and prognosis of acute liver failure during pregnancy? J Med Virol 2013; 85: 620-626.

24 Piratvisuth T. Optimal management of $\mathrm{HBV}$ infection during pregnancy. Liver Int 2013; 33(Suppl. 1): 188 194.

25 European Association for the Study of the Liver. EASL clinical practice guidelines: management of chronic hepatitis B virus infection. J Hepatol 2012; 57: 167-185.

26 Beasley RP, Trepo C, Stevens CE, Szmuness W. The e antigen and vertical transmission of hepatitis $B$ surface antigen. Am J Epidemiol 1977; 105: 94-98.

27 Mast EE, Hwang LY, Seto DS et al. Risk factors for perinatal transmission of hepatitis $\mathrm{C}$ virus (HCV) and the natural history of $\mathrm{HCV}$ infection acquired in infancy. $J$ Infect Dis 2005; 192: 1880-1889.

28 Tan J, Surti B, Saab S. Pregnancy and cirrhosis. Liver Transpl 2008;

8 14: 1081-1091.

29 Pan CQ, Duan ZP, Bhamidimarri KR et al. An Algorithm for risk 
assessment and intervention of mother to child transmission of hepatitis B virus. Clin Gastroenterol Hepatol 2012; 10: 452-459.

30 Tse KY, Ho LF, Lao T. The impact of maternal HBsAg carrier status on pregnancy outcomes: a case-control study. J Hepatol 2005; 43: 771-775.

31 Degli Esposti S, Shah D. Hepatitis B in pregnancy: challenges and treatment. Gastroenterol Clin North Am 2011; 40(2): 355-372.

32 Borgia G, Carleo MA, Gaeta GB, Gentile I. Hepatitis B in pregnancy. World J Gastroenterol 2012; 18: 4677-4683.

33 Foster C, Lyall H, Olmscheid B, Pearce G, Zhang S, Gibb DM. Tenofovir disoproxil fumarate in pregnancy and prevention of mother-to-child transmission of HIV-1: is it time to move on from zidovudine? HIV Med 2009; 10: 397-406.

34 Keefe EB, Dieterich DT, Han S-HB et al. A treatment algorithm for the management of chronic hepatitis $B$ virus infection in the United States: an update. Clin Gastroenterol Hepatol 2006; 4: 936-962.

35 Nguyen G, Garcia RT, Nguyen N, Trinh H, Keeffe EB, Nguyen MH. Clinical course of hepatitis B virus infection during pregnancy. Aliment Pharmacol Ther 2009; 29: 755-764.

36 Liu M, Cai H, Yi W. Safety of telbivudine treatment for chronic hepatitis B for the entire pregnancy. J Viral Hepat 2013; 20(Suppl. 1): 65-70.

37 Chen X, Chen J, Wen J et al. Breastfeeding is not a risk factor for mother-to-child transmission of hepatitis B virus. PLoS One 2013; 8: e55303.

38 Bzowej NH. Hepatitis B therapy in pregnancy. Curr Hepat Rep 2010; 9: 197-204.

39 Valdés R, Sepúlveda MA, Candia PP, Lattes AK. Acute viral hepatitis during pregnancy. Rev Chilena Infectol 2010; 27: 505-512.

40 Le Campion A, Larouche A, Fauteux-Daniel S, Soudeyns H. Patho- genesis of hepatitis C during pregnancy and childhood. Viruses 2012; 4: 3531-3550.

41 Mor G, Cardenas I. The immune system in pregnancy: a unique complexity. Am J Reprod Immunol 2010; 63: 425-433.

42 Floreani A. Hepatitis C and pregnancy. World J Gastroenterol 2013; 19: 6714-6720.

43 Pergam SA, Wang CC, Gardella CM, Sandison TG, Phipps WT, Hawes SE. Pregnancy complications associated with hepatitis C: data from a 2003-2005 Washington state birth cohort. Am J Obstet Gynecol 2008; 199: 38.e1-38.e9.

44 Paternoster DM, Fabris F, Palù G et al. Intra-hepatic cholestasis of pregnancy in hepatitis $\mathrm{C}$ virus infection. Acta Obstet Gynecol Scand 2002; 81: 99-103.

45 Paternoster DM, Belligoli A, Ngaradoumbe NK et al. Endogenous interferon-alpha level is increased in hepatitis $\mathrm{C}$ virus (HCV)-positive pregnant women. J Clin Gastroenterol 2008; 42: 204-207.

46 Gervais A, Bacq Y, Bernuau J et al. Decrease in serum ALT and increase in serum HCV RNA during pregnancy in women with chronic hepatitis C. J Hepatol 2000; 32: 293-299.

47 Roberts EA, Yeung L. Maternalinfant transmission of hepatitis C virus infection. Hepatology 2002; 36 (5 Suppl. 1): S106-S113.

48 Indolfi G, Resti M. Perinatal transmission of hepatitis $\mathrm{C}$ virus infection. J Med Virol 2009; 81: 836843.

49 Pembrey L, Newell ML, Tovo PA, EPHN Collaborators. The management of HCV infected pregnant women and their children European paediatric HCV network. J Hepatol 2005; 43: 515-525.

50 Powell M, Bailey J, Maggio LA. Clinical inquiries. How should you manage children born to hepatitis
C-positive women? J Fam Pract 2010; 59: 289-290.

51 Arshad M, El-Kamary SS, Jhaveri R. Hepatitis $\mathrm{C}$ virus infection during pregnancy and the newborn periodare they opportunities for treatment? J Viral Hepat 2011; 18: 229-236.

52 Garg V, van Heeswijk R, Yang Y, Kauffman R, Smith F, Adda N. The pharmacokinetic interaction between an oral contraceptive containing ethinylestradiol and norethindrone and the HCV protease inhibitor telaprevir. J Clin Pharmacol 2012; 52: 1574-1583.

53 Russell MA, Craigo SD. Cirrhosis and portal hypertension in pregnancy. Semin Perinatol 1998; 22: 156-165.

54 Shaheen AA, Myers RP. The outcomes of pregnancy in patients with cirrhosis: a population-based study. Liver Int 2010; 30: 275-283.

55 Cheng YS. Pregnancy in liver cirrhosis and/or portal hypertension. Am J Obstet Gynecol 1977; 128: 812-822.

56 Misra S, Sanyal AJ. Pregnancy in a patient with portal hypertension. Clin Liver Dis 1999; 3: 147-162.

57 Helmy A, Hayes PC. Review article: current endoscopic therapeutic options in the management of variceal bleeding. Aliment Pharmacol Ther 2001; 15(5): 575-594.

58 Coscia LA, Constantinescu S, Moritz MJ et al. Report from the National Transplantation Pregnancy Registry (NTPR): outcomes of pregnancy after transplantation. Clin Transpl 2010; ????: 65-85.

59 Armenti VT. Pregnancy after liver transplantation. Liver Transpl 2012; 18: 619-620.

60 Paternoster DM, Floreani A, Burra P. Liver transplantation and pregnancy. Int J Gynaecol Obstet 1995; 50(2): 199-200. 


\section{Author Query Form}

Journal: $\quad$ JVH

Article: $\quad 12335$

Dear Author,

During the copy-editing of your paper, the following queries arose. Please respond to these by marking up your proofs with the necessary changes/additions. Please write your answers on the query sheet if there is insufficient space on the page proofs. Please write clearly and follow the conventions shown on the attached corrections sheet. If returning the proof by fax do not write too close to the paper's edge. Please remember that illegible mark-ups may delay publication.

Many thanks for your assistance.

\begin{tabular}{|c|c|c|}
\hline Query reference & Query & Remarks \\
\hline 1 & $\begin{array}{l}\text { AUTHOR: A running head short title was not supplied; please check if this one is } \\
\text { suitable and, if not, please supply a short title of up to } 40 \text { characters that can be } \\
\text { used instead. }\end{array}$ & \\
\hline 2 & AUTHOR: Please check the text of summary. & \\
\hline 3 & $\begin{array}{l}\text { AUTHOR: The set of keywords is extracted from the supplied PDF source file. } \\
\text { Please check if the keywords are okay. }\end{array}$ & \\
\hline 4 & AUTHOR: Please check the heading levels. & \\
\hline 5 & $\begin{array}{l}\text { AUTHOR: Please check this website address and confirm that it is correct. (Please } \\
\text { note that it is the responsibility of the author(s) to ensure that all URLs given in } \\
\text { this article are correct and useable.) }\end{array}$ & \\
\hline 6 & $\begin{array}{l}\text { AUTHOR: Please check the edit made in the sentence "The Immunosuppresive... in } \\
\text { animals". }\end{array}$ & \\
\hline 7 & AUTHOR: Please provide the article title for reference [21]. & \\
\hline 8 & $\begin{array}{l}\text { AUTHOR: References [28] and [58] are identical. Hence, reference [58] is deleted } \\
\text { and rest of the references is renumbered. Please check. }\end{array}$ & \\
\hline 9 & AUTHOR: Please provide the volume number for reference [58]. & \\
\hline
\end{tabular}

